\title{
FLOW IN THE ENGINE COMPARTMENT: ANALYSIS AND OPTIMIZATION
}

\author{
D’Hondt M., Gilliéron P.
}

RENAULT

Direction de la Recherche, des Études Avancées et Matériaux, 1 Avenue du Golf, 78288 GUYANCOURT France

email : patrick.gillieron@renault.com

\section{Devinant $P$.}

\author{
INSTITUT PRISME \\ Polytech'Orléans \\ 8 rue Léonard de Vinci, 45072 ORLEANS Cedex 2, France
}

\begin{abstract}
In the current sustainable development context, car manufacturers have to keep doing efforts to reduce the aerodynamic drag of automotive vehicle, and consequently their $\mathrm{CO}_{2}$ and greenhouse gas emissions. The cooling airflow through the engine compartment of vehicles contributes from $5 \%$ to $10 \%$ to the total aerodynamic drag. By means of a simplified car geometry, equipped with an engine compartment, flow in the engine compartment is analyzed by three complementary approaches: an experimental approach, a numerical approach and an analytical approach. The experimental approach is mainly used to measure drag values and to explain the drag variations induced by modifications of the outlet location. The purpose of the numerical simulations is to evaluate the flow rates through the engine compartment and particularly through the heat exchangers. Finally, the analytical approach establishes a model to connect the aerodynamic drag with the cooling flow rate. Configurations favorable to low cooling drag values and high cooling flow rates are identified. They correspond to vehicles with an engine compartment outlet located at the rear end.
\end{abstract}

Keywords: Engine Compartment, Cooling Drag, Particle Image Velocimetry.

\section{Biographical notes:}

D'Hondt M. is an engineer and is currently working towards a doctoral degree, concentrating her research effort in the field of fluid dynamics by numerical and experimental investigations.

Gilliéron P. is a researcher and responsible for the research group "Fluid Mechanics and Aerodynamics" of Renault. His work concerns mainly the control of the separations and the transient phenomena.

Devinant P. is professor at the "PRISME" Institute of the University of Orléans, in the team "Flows and Aerodynamic Systems". He is mainly involved in researches about low speed aerodynamic flows characterization and control. 
D’Hondt M., Gilliéron P., Devinant P.

\section{Introduction}

In the current sustainable development context, sectors responsible for the atmospheric pollution are more and more constrained. In Europe, the contribution of the ground transportation sector to the atmospheric pollution reaches $26 \%$ [1]. Consequently, European regulations control emissions of $\mathrm{CO}_{2}$ and greenhouse gas effect. In 2012, the new vehicle $\mathrm{CO}_{2}$ emissions will not exceed 120 grams per kilometre and 95 grams per kilometre in 2020 [1]. Thus, car manufacturers have to find new solutions to reduce the vehicle emissions. One way to reach this goal is to reduce the aerodynamic drag. On motor vehicles, the drag sources are clearly identified and one of them corresponds to the cooling airflow.

The cooling drag coefficient $\mathrm{C}_{\mathrm{D}}$ (cooling) is evaluated in wind tunnels by successively measuring the aerodynamic drag of the vehicle with opened and then closed air inlets. Since 1978 , the contribution of the cooling drag into the total drag generally amounts from $5 \%$ to $10 \%$ [2-5]. Investigating the cooling airflow is then a way to reduce the total drag. Moreover, the amount of flow through the engine compartment is determined by the front end vehicle geometry, the cooling system package and the engine compartment geometry, including the inlet and outlet sections [6-8]. The internal flow is complex and divided into several circuits [9]. The issue associated with the cooling airflow is then complex since it needs to provide both a sufficient cooling and a low cooling drag.

Experimental and analytical works on the engine compartment show that the outlet location is of great importance for the cooling drag [3,6,10,11]. Results show that a rear end location is more favourable to a low cooling drag than an underbody location. Nevertheless, the phenomena responsible for these drag variations are not clearly identified. Experimental tests also show that the velocity distribution on the heat exchangers influences the quality of the cooling [12]. The more uniform the velocity distribution is, the better the cooling is. Nonetheless, no link has been established between the airflow uniformity through the heat exchangers and the cooling drag.

Numerical simulations give more and more accurate results for both external aerodynamics and cooling airflow predictions $[7,8]$. Moreover, numerical results give an easy access to flow rates, velocity distributions and recirculation zones that are difficult to obtain with experimental investigations.

Finally, analytical studies attempt to give an analytical expression of the cooling drag as a function of data measured on the heat exchangers [4,11] or at the inlet and outlet sections [6]. Nevertheless, they do not use the cooling drag usual definition as previously described. Another approach is to make an analogy between fluid flows and electrical circuits [12]. This approach, by means of a zero dimension model, is able to provide drag and cooling flow rate evolutions as functions of geometrical modifications of the vehicle. This tool could be used in the early stages of a vehicle development.

This paper seeks to contribute to the prior literature by several ways. In this way, the three approaches found in the literature are used to study the cooling airflow. The experimental approach provides drag and velocity measurements, in order to give a better understanding of the physical phenomena. Numerical simulations are mostly used to evaluate the flow rates through the engine compartment and the heat exchangers, to identify configurations favourable to the engine cooling and to see how they match with configurations favourable to a low cooling drag. Finally, the analytical approach develops a model to connect the flow rate through the engine compartment with the aerodynamic drag of the geometry. Knowledge of the internal geometry of the engine compartment gives also access to the flow rate through every path of the air circuit. 


\section{Setup}

A simplified car geometry equipped with an engine compartment is studied in terms of cooling drag and cooling flow rate by means of experimental, numerical and analytical investigations.

The simplified car geometry is based on an Ahmed body with a blunt rear end (Fig. 1). Its length, width and height are respectively $\mathrm{L}=0.532 \mathrm{~m}, \mathrm{l}=0.389 \mathrm{~m}$ and $\mathrm{H}=0.288 \mathrm{~m}$. The inlet section of the engine compartment is located at the front end of the geometry. The outlet section can have five different locations, at the underbody or at the base of the geometry. Exits 1,2 and 3 are located in the underbody at $0.68 \times \mathrm{L}$, respectively $0.27 \times \mathrm{L}$ and $0.03 \times \mathrm{L}$ from the base. Exits 4 and 5 are situated at the base, at $0.04 \times \mathrm{H}$ and $0.51 \times \mathrm{H}$ from the underbody. Inlet and outlet sections are equipped with grilles composed of four tilting blades. During the tests, only one outlet is used at a time and five inclinations of the blades are experimented in the inlet section and in each of the outlet sections (see Fig. 1 for the inclination values). It then allows 125 geometrical configurations since there are five possible inclinations in the inlet section, five possible outlets and five possible inclinations in the outlet section.

The air circuit of the engine compartment comprises a porous media modelling the heat exchangers and a cross-section of a real engine to simulate the engine volume (Fig. 1). Holes are uniformly distributed on the porous media surface (Fig. 2) to obtain the porosity, defined by the ratio of opened surface on total surface, of a middle range radiator, which amounts to 0.5 . For outlets $1,2,3$ and 4 , the air circuit is the same but the location of outlet 5 at the middle of the geometry base requires a modification of the air circuit. This second air circuit is indicated with dashed lines in Fig. 1. The width of the air circuit is constant and represents almost 1/4 of the geometry width (Fig. 2). It allows considering the internal flow as a 2-D flow.

The simplified geometry described here is used for the three approaches presented in this paper. The experimental results are firstly commented and concern all of the 125 geometrical configurations.

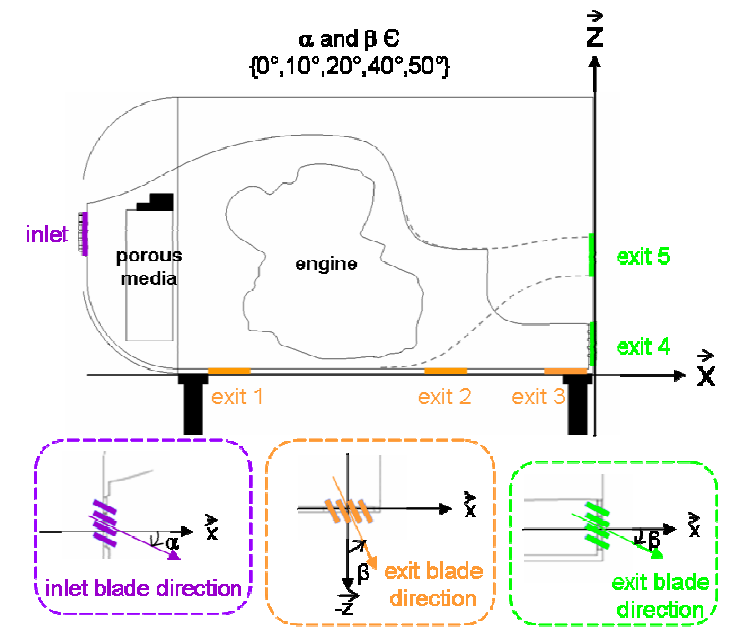

Fig. 1 Simplified car geometry equipped with an engine compartment
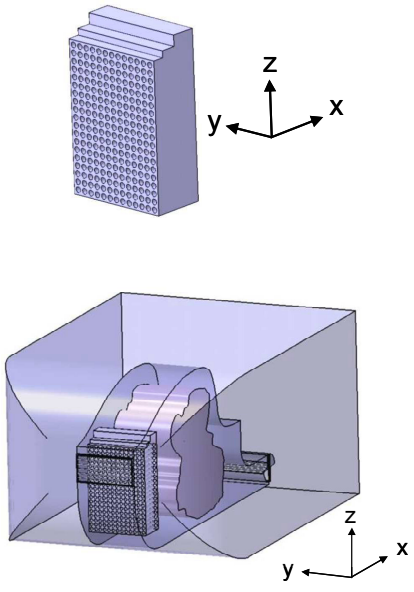

Fig. 2 Porous media and simplified geometry in 3-D view 


\section{Experimental results}

The experimental investigation is performed in the wind tunnel 'Lucien Malavard' of the PRISME Institute of the University of Orléans. The test section is $5 \mathrm{~m}$ long and the crosssection is $2 \times 2 \mathrm{~m}^{2}$. As shown in Fig. 1, the simplified geometry is mounted on four cylindrical tubes of $0.02 \mathrm{~m}$ diameter and $0.07 \mathrm{~m}$ height. This height represents the ground clearance. The geometry is placed on a plate located at $0.4 \mathrm{~m}$ from the floor. This plate controls the boundary layer development. The boundary layer thickness is between $1.7 \times 10^{-2} \mathrm{~m}$ and $1.2 \times 10^{-2} \mathrm{~m}$ for free stream velocities between $10 \mathrm{~m} \cdot \mathrm{s}^{-1}$ and $50 \mathrm{~m} \cdot \mathrm{s}^{-1}$. During all the tests, the free stream velocity is set to $30 \mathrm{~m} \cdot \mathrm{s}^{-1}$.

Drag measurements are performed for the 125 configurations specified in the previous section. Even though not all the results are presented here, the measurements show that increasing the inlet inclination generates a cooling drag reduction [5]. Since the cooling drag evolution trend in function of the outlet blade inclination does not vary with the inlet blade inclination, only results for a $0^{\circ}$ inlet blade inclination are presented (Fig. 3).

The results show that the highest cooling drag values are obtained with outlet 3 , located in the underbody of the geometry near the base. They are then followed by values of outlets $1 \& 2$ located farther from the base than outlet 3 , but still in the underbody. The lowest cooling drag values are finally given by outlets $4 \& 5$ located at the base of the geometry.

Concerning contribution of the cooling drag into the total drag, the same trend is observed. The highest values are obtained with the underbody outlets (\# 1, 2 \& 3) especially with outlet 3 , and the lowest values with the base outlets (\# $4 \& 5$ ). Outlets $1 \&$ 2 are the most representatives of a real vehicle both by their position in the underbody and by the cooling drag contribution into their total drag.

These results agree with the literature: an outlet located at the base of the geometry favors low cooling drag values compared to an outlet located in the underbody. Nevertheless, great differences are obtained between outlets situated in the underbody as for outlets 2 and 3. To explain these important drag variations, velocity measurements are performed in the wake of the geometry.

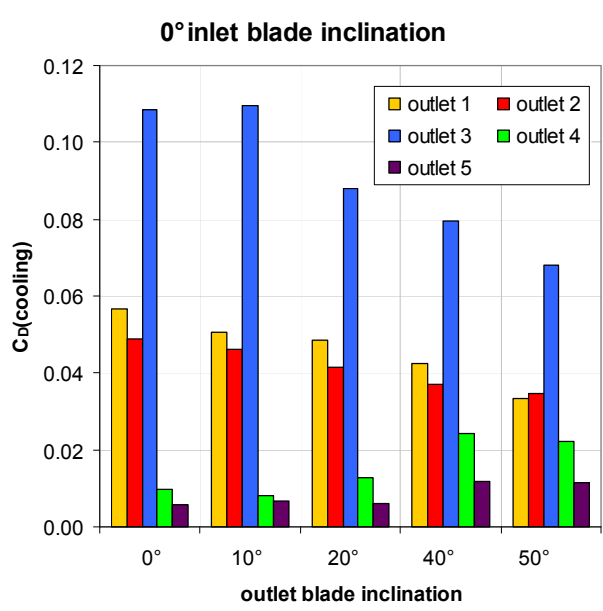

Fig. 3 Cooling drag measurements for the five outlets of the engine compartment

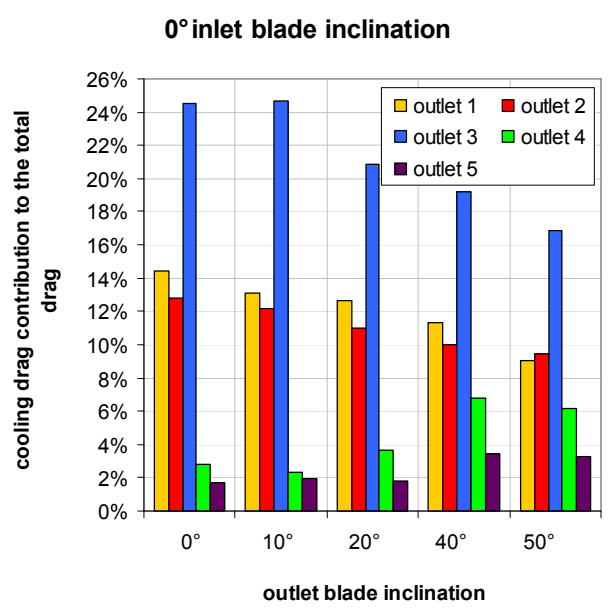

Fig. 4 Cooling drag contribution into the total drag of the simplified geometry 
In order to measure the velocity field in the wake of the geometry, the PIV (Particle Image Velocimetry) technique is used. Measurement are performed in the symmetrical plane $\mathrm{y}=0$ and two fields of $400 \times 400.10^{-6} \mathrm{~m}^{2}$ each are required to cover the whole wake structure (Fig. 5). The PIV measurements are restricted to outlets 2, 3, $4 \& 5$ since outlet 1 has the same order of cooling drag than outlet 2 . Moreover, only the $10^{\circ}$ and $40^{\circ}$ outlet blade inclinations are studied since they respectively generate the lowest and highest drag values associated to outlets $4 \& 5$.
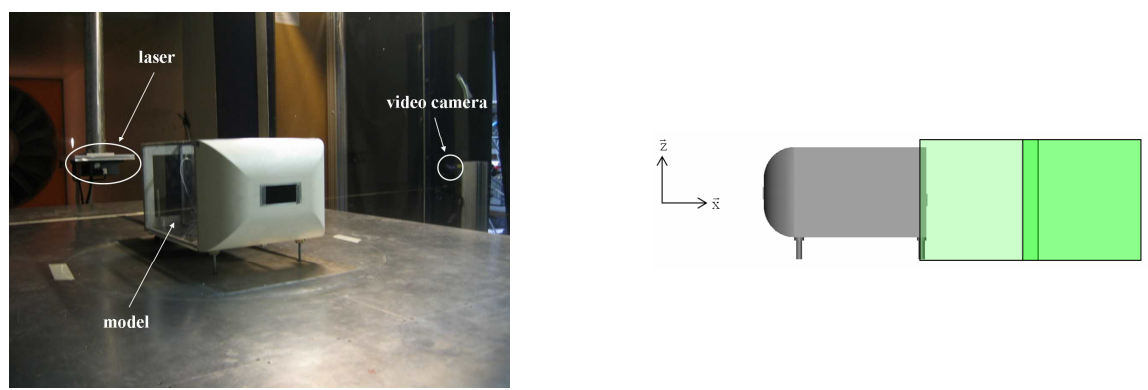

Fig. 5 PIV measurements

The PIV velocity measurements (Fig. 6) show that the streamwise wake is composed of two contrarotating vortices. They result from a toric structure that attaches to the base (see also [14-16]). In the streamwise plane $y=0$, the vortices cores are respectively noted $\mathrm{T}_{1}$ for the upper structure and $\mathrm{T}_{2}$ for the lower structure. The outlet location modifies the velocity magnitude and direction of the underbody flow and consequently the cores positions. For instance, the use of outlets $2 \& 3$, located in the underbody of the geometry, provides lower underbody velocity than the closed section configuration. Therefore, the cores $\mathrm{T}_{1}$ and $\mathrm{T}_{2}$ stand nearer to the geometry base. On the contrary, the use of outlets $4 \& 5$, located at the base, introduces momentum in the wake and the cores $T_{1}$ and $\mathrm{T}_{2}$ move downstream from the geometry. It then appears that the farther the cores are located from the base of the geometry, the lower the drag values are. Indeed, with vortices cores far from the base, the velocity decreases near the base and is accompanied with an increase in the base static pressure. A static pressure increase at the base being equivalent to a drag reduction, the drag variation is directly connected to the vortices cores locations in the wake. 
D'Hondt M., Gilliéron P., Devinant P.

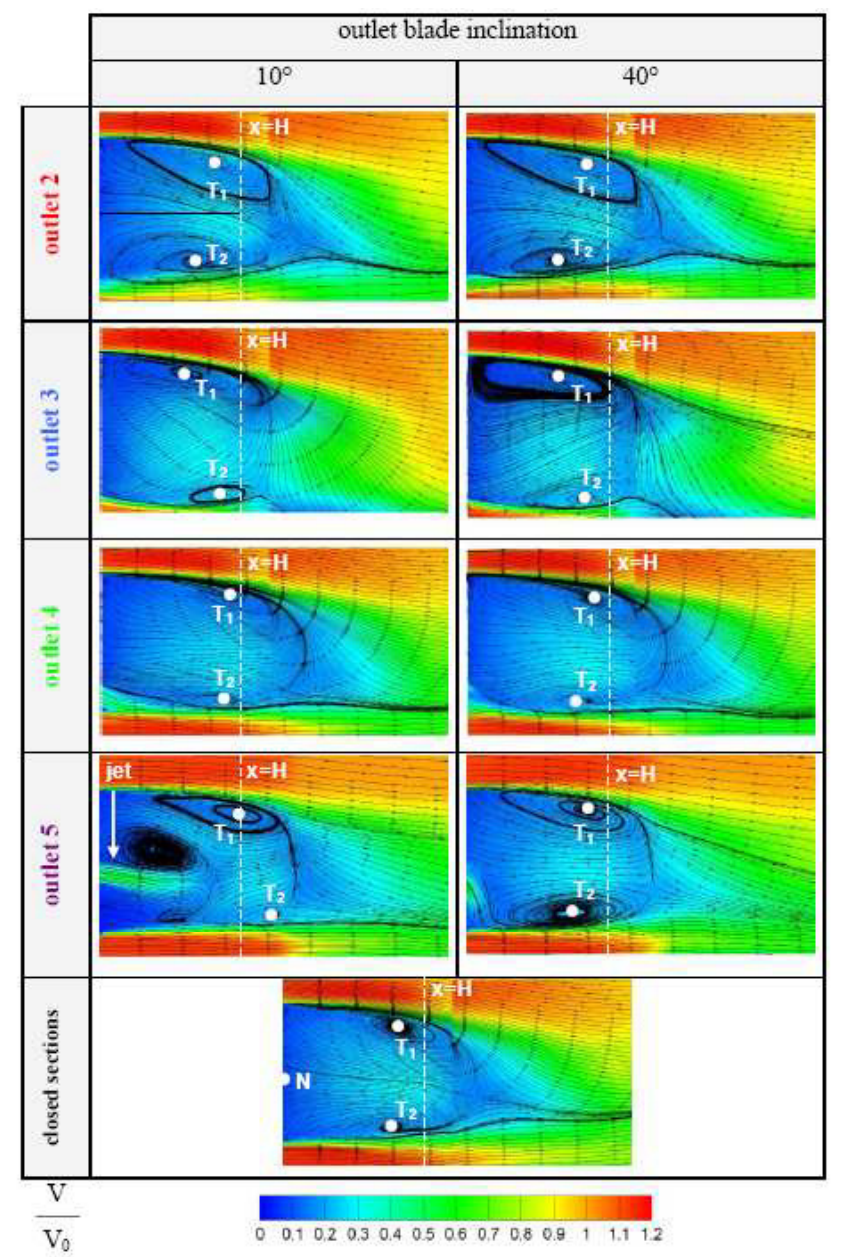

Fig. 6 Experimental velocity measurements in the wake of the geometry

\section{Numerical results}

In this section, numerical results are used in complement to the experimental results to identify and quantify the drag sources of the geometry from velocities and total pressure values. They are then used to evaluate the flow rates through the engine compartment and through each branch of the internal air circuit.

Numerical simulations are performed with a commercial CFD code based on the Lattice Boltzmann Method [18]. This code shows good correlation between experimental and numerical results for both external aerodynamics and cooling airflow [8]. The code is based on the principle of performing very large eddy simulations (VLES) that directly simulate resolvable flow scales while modeling unresolved scales. It incorporates the state-of-the-art renormalization group (RNG) form of the k-epsilon equations with proprietary extensions to achieve VLES time accurate physics. The effects of the unresolved (subgrid) scale flow properties on the resolved large scales are realized via eddy viscosity and turbulent Prandtl numbers (see [18]). 
The meshed geometry is integrated into a numerical wind tunnel that does not have the same dimensions of the real wind tunnel in order to avoid side effects, blockage effects and interactions between the boundary conditions and the flow development around the geometry. The length, width and height of the numerical wind tunnel are respectively $100 \times \mathrm{H}, 20 \times \mathrm{H}$ and $18 \times \mathrm{H}$. The boundary conditions reproduce a road condition flow. $\mathrm{A} \mathrm{V}_{0}$ free stream velocity is imposed on the calculation domain inlet, and a free flow direction in the domain outlet, with a static pressure equal to the atmospheric pressure. The other walls (side walls, ceiling and floor) are defined as frictionless walls without boundary layer. Except for the porous media, the geometry is represented by walls where a turbulent boundary layer develops. The Darcy's law (relation (1)) is used to characterize the porous media pressure drop $\Delta \mathrm{Pi}$ along its thickness $\mathrm{L}_{\mathrm{pm}}$ as a function of the flow velocity $\mathrm{V}$ through it.

$$
\frac{\Delta \mathrm{Pi}}{\mathrm{L}_{\mathrm{pm}}}=-\rho\left(\mathrm{C}_{\mathrm{V}_{\mathrm{x}}}+\mathrm{C}_{\mathrm{I}_{\mathrm{x}}}|\mathrm{V}|\right) \mathrm{V}_{\mathrm{x}} .
$$

The coefficients $\mathrm{C}_{\mathrm{V}_{\mathrm{x}}}$ and $\mathrm{C}_{\mathrm{I}_{\mathrm{x}}}$ respectively represent the viscous and inertial coefficients of resistance along the free stream direction $\mathrm{x}$.

A restricted number of configurations is studied by numerical simulations. They are based on the previous drag measurements results. For a $0^{\circ}$ inlet blade inclination, a $10^{\circ}$, respectively a $0^{\circ}$, outlet blade inclination gives the lowest drag value for outlet 4 , respectively outlet 5 . They are thus studied numerically. For outlets $2 \& 3$, a $40^{\circ}$ outlet blade inclination is chosen since it has one of the lowest drag values associated to these outlets. Besides, this inclination corresponds to the highest drag values of outlets $4 \& 5$.

For a notchback vehicle, Onorato et al. [19] show that the aerodynamic drag can be analytically expressed from velocities and total pressure distributions in the spanwise wake section $\mathrm{S}$ (relation (2)). In this case, the spanwise plane is located at $1.1 \times \mathrm{H}_{\text {vehicle }}$ and the difference between the analytical and measured drag values rises to $-1.3 \%$.

$$
\mathrm{D}(\text { Onorato })=\underbrace{\iint_{\mathrm{S}}\left(\mathrm{Pi}_{0}-\mathrm{Pi}\right) \mathrm{d} \sigma}+\frac{\rho \mathrm{V}_{0}^{2}}{2} \iint_{\mathrm{S}}\left(\frac{\mathrm{V}_{\mathrm{y}}^{2}}{\mathrm{~V}_{0}^{2}}+\frac{\mathrm{V}_{\mathrm{z}}^{2}}{\mathrm{~V}_{0}^{2}}\right) \mathrm{d} \sigma
$$

$$
+\underbrace{\frac{-\rho V_{0}^{2}}{2} \iint_{S}\left(1-\frac{V_{x}}{V_{0}}\right)^{2} d \sigma \text {. }}
$$

For the simplified car geometry equipped with an engine compartment, the spanwise planes are located at $0.5 \times \mathrm{H}, \mathrm{H}, 2 \times \mathrm{H}, 3 \times \mathrm{H}$ and $3.7 \times \mathrm{H}$. The difference between the drag coefficients values calculated from relation (2), noted $\mathrm{C}_{\mathrm{D}}$ (Onorato), and calculated by the code, noted $\mathrm{C}_{\mathrm{D}}$ (code), is shown in Fig. 7. The results show that a distance $2 \times \mathrm{H}$ downstream to the geometry gives the best drag estimation by the Onorato's relation for outlets 2, 3 and 4. The hypotheses used by Onorato and al. explain that a longer distance is necessary compared to a notchback vehicle. Indeed, the authors do not take into account the viscosity and turbulence strains in the drag expression and they consider a steady flow. The streamwise velocity fields in Fig. 6 show that at a distance $\mathrm{H}$ downstream to the geometry, turbulence effects can not be neglected. For outlet 5, a distance $3 \times \mathrm{H}$ downstream to the geometry is necessary. The jet flow coming out of outlet 5 seems to favor mixing enhancement and thus turbulence effects. 
It is then possible to evaluate the terms (a), (b) and (c) of the Onorato's relation (relation (2)) and to quantify their contribution into the total drag. The results, presented in Fig. 8, show that for all of the outlets, the highest contribution into the total drag is given by the term (a), which represents the total pressure drop due to the geometry. This contribution is between $65 \%$ and $78 \%$. The second highest contribution corresponds to the term (c), which depends on the change in longitudinal flow velocity. It contributes from $20 \%$ to $28 \%$ into the total drag. Finally, the lowest contribution goes with the term (b) which expresses the flow rotation in the spanwise plane. In the case of outlet 3 , the streamwise wake is oriented towards the floor (see Fig. 6) and the $\mathrm{V}_{\mathrm{z}}$ velocity component increases compared to the other configurations. It explains why outlet 3 gives the highest value of the term (b). To reduce the aerodynamic drag of the simplified car geometry equipped with an engine compartment, it is then necessary to reduce the total pressure drop. In the case of a blunt rear end vehicle, the velocities near the base are very low and the total pressure is mostly given by the static pressure. Hence, a way to reduce the drag would be to increase the static pressure at the base of the vehicle. It agrees with the previous experimental conclusions.

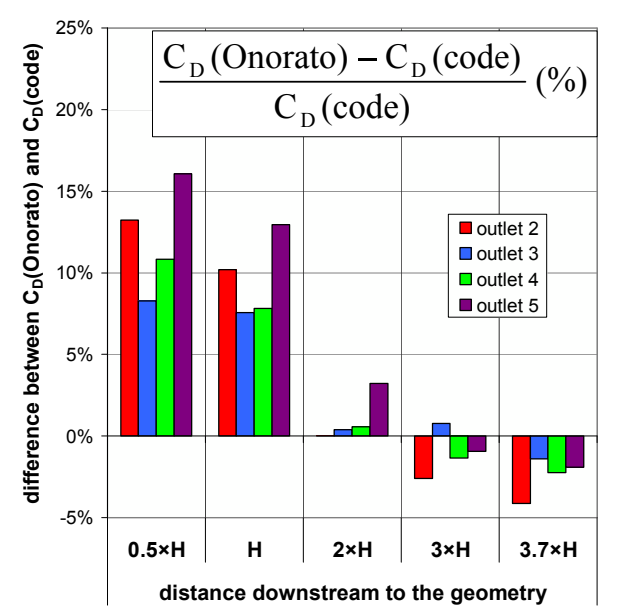

Fig. 7 Difference between the drag values $\mathrm{C}_{\mathrm{D}}($ Onorato $)$ and $\mathrm{C}_{\mathrm{D}}$ (code)

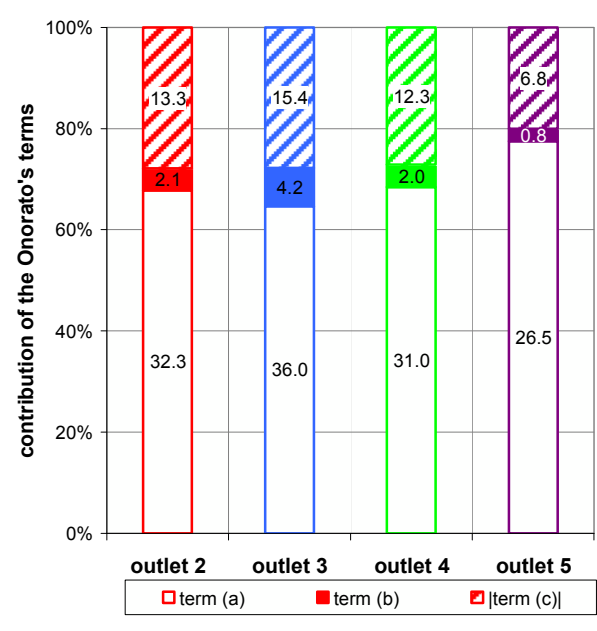

Fig. 8 Values and contributions of the Onorato's terms

Numerical simulations allow the evaluation of the flow rates through the engine compartment and through every path of the internal air circuit. The results, presented in Fig. 9, show that the highest flow rates through the engine compartment, and particularly through the porous media, are given by outlets $4 \& 5$ located at the base of the geometry. On the opposite, the lowest flow rates are obtained with outlets $2 \& 3$ located in the underbody of the geometry. The hierarchy between the outlets is the same for the drag and flow rate values: outlets located at the base of the geometry give the lowest drag values and the highest flow rates through the heat exchangers; and outlets located in the underbody generate the highest drag values and the lowest flow rates.

Moreover, for all of the exits, almost $65 \%$ of the flow entering the engine compartment crosses the porous media representing the heat exchangers. It means that $35 \%$ of the cooling airflow is not used by the cooling system. Therefore, a solution to improve the engine cooling is to remove the flows above and below the porous media.

The drag and flow rates variations associated to this solution are presented in Fig. 10. The results show that despite the reduction of the flow rate in the inlet section, the sealed 
configurations allow an important increase of the flow rate through the porous media of almost $45 \%$ for each outlet. Besides, the use of this solution has little impact on the drag values (Fig. 10).

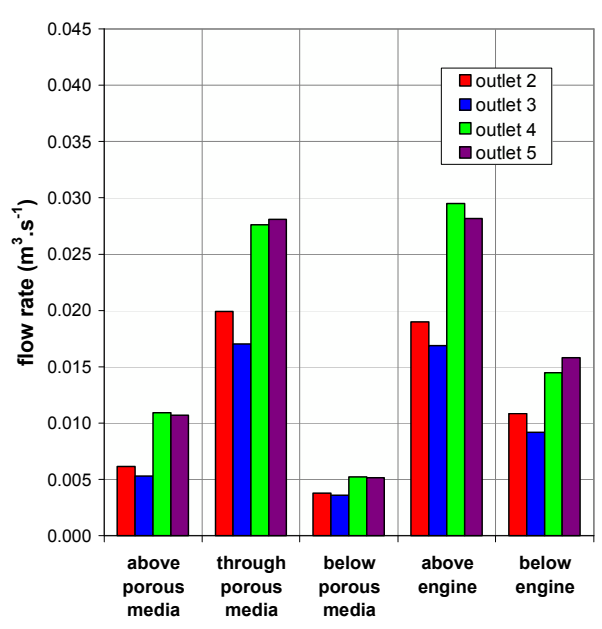

Fig. 9 Flow rates in the engine compartment

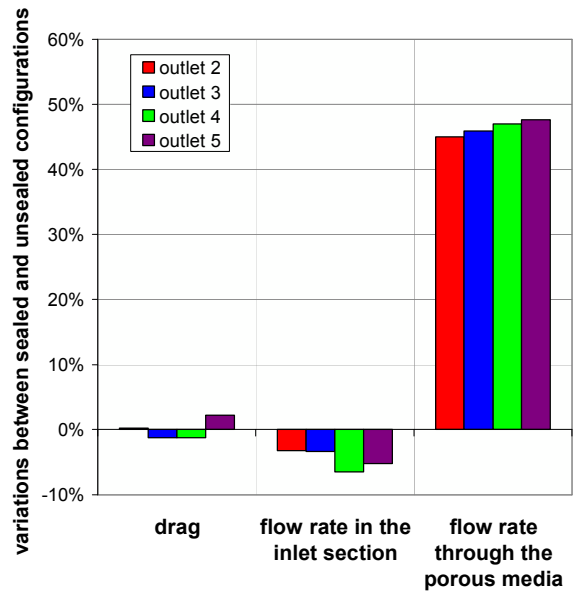

Fig. 10 Variations of drag and flow rates between the sealed and unsealed configurations

The numerical results give also access to the velocity distribution on the exposed face of the porous media. The result for the configuration that has the highest flow rates values, outlet 5, is presented in Fig. 11. The result shows that the velocity distribution on the exposed face of the porous media is not uniform and the upper part of the porous media is much more supplied with air than the lower part. This is explained by the location of the inlet section that faces the upper part of the porous media.

The evaluation of the pressure drop of the porous media is achieved by two different ways. In one case, the pressure is numerically evaluated on the front end, and the rear end of the porous media and the pressure drop is calculated by the difference between these two values. In the other case, the average flow rate through the porous media (see Fig. 9) is put into the Darcy's law to calculate the pressure drop of the porous media. These two methods do not give the same pressure drops values (see Fig. 12). This is explained by the non-uniformity of the velocity distribution on the porous media. From these results, it can be seen that a uniform velocity distribution (see the Darcy's law results in Fig. 12) allows reducing the porous media pressure drop. Since the heat exchanger provides most of the pressure loss in a typical cooling system [11] and since the pressure drop is directly connected with the aerodynamic drag in the case of a blunt rear end vehicle [13], a uniform velocity distribution on the heat exchanger may consist in a solution to reduce the vehicle drag. 
D’Hondt M., Gilliéron P., Devinant P.

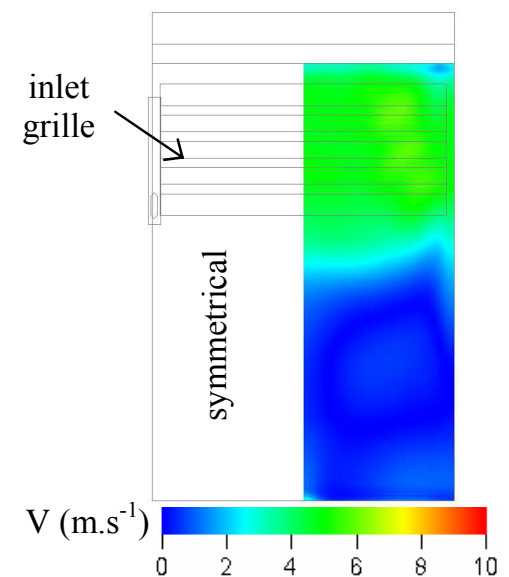

Fig. 11 Velocity distribution on the exposed face of the porous media for exit 5

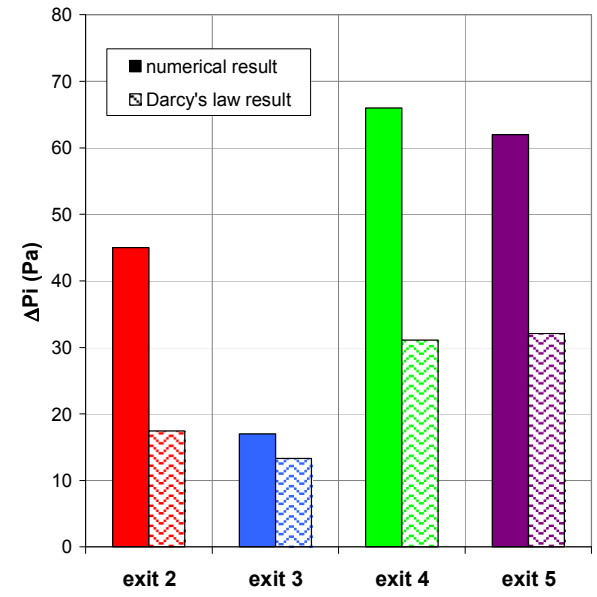

Fig. 12 Difference between the porous media pressure drop

\section{Analytical results}

In this section, an analytical model is developed to connect the aerodynamic drag of the simplified car geometry with the flow rate through the engine compartment. The validation of this approach is based on numerical results but it intends to provide flow rates estimations in the early stages of a vehicle development.

The model development is based on the analogy between electrical and fluid circuits. Three properties are used to characterize a circuit noted $\mathrm{k}$ : a flow rate $\mathrm{q}_{\mathrm{k}}$, a total pressure drop $\Delta \mathrm{Pi}_{\mathrm{k}}$ and an aperture $\mathrm{O}_{\mathrm{k}}$. They are linked by the following relation:

$$
\Delta \mathrm{Pi}_{\mathrm{k}}=\frac{\rho}{2}\left(\frac{\mathrm{q}_{\mathrm{k}}}{\mathrm{O}_{\mathrm{k}}}\right)^{2}
$$

The external and internal flows associated to the simplified car geometry are decomposed into elementary circuits that are presented in Fig. 13 and Fig. 14. The external flow is divided into three circuits (Fig. 13): circuit I that goes over and on the geometry sides, circuit II that crosses the engine compartment and circuit III in the underbody of the geometry. Next, circuit II is divided into three circuit flows (Fig. 13): circuit 1 upstream from the engine compartment, circuit 10 between its inlet and outlet sections, and circuit 9 downstream from the engine compartment. This decomposition is only applicable for an outlet located at the base of the geometry. This kind of configuration is chosen since it provides the lowest drag values and the highest cooling flow rates. The internal flow is decomposed into seven circuit flows (Fig. 14): above (circuit 2), through (circuits 3a and $3 \mathrm{~b}$ ) and below (circuit 4) the porous media, above (circuit 7) and below (circuit 8) the engine, and the flows that go out of the porous media from the upper (circuit 5), respectively lower (circuit 6), part of it. 


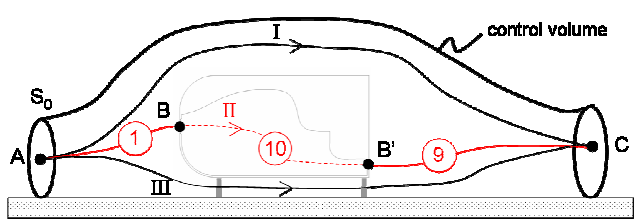

Fig. 13 External flow decomposition

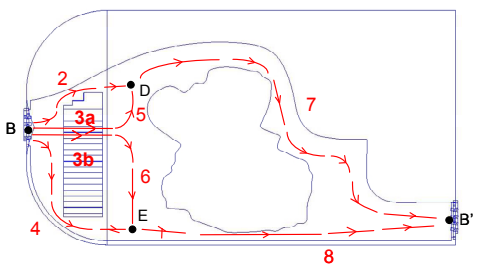

Fig. 14 Internal flow decomposition

The external flow decomposition (Fig. 13) is equivalent to an electrical circuit composed of three parallel branches. Therefore, the total pressure drop $\Delta \mathrm{Pi}_{\mathrm{II}}$ is equal to the total pressure drop $\Delta \mathrm{Pi}_{\mathrm{AC}}$ between points $\mathrm{A}$ and $\mathrm{C}$. For a squareback geometry, with very low velocities near the base, the total pressure drop $\Delta \mathrm{Pi}_{\mathrm{AC}}$ is expressed as a function of the average base static pressure noted $\mathrm{Cp}_{\text {base }}[13]$ :

$$
\Delta \mathrm{Pi}_{\mathrm{II}}=\Delta \mathrm{Pi}_{\mathrm{AC}} \approx \frac{1}{2} \rho \mathrm{V}_{0}^{2}\left(1-\mathrm{Cp}_{\text {base }}\right)
$$

According to relation (3), the flow rate $\mathrm{q}_{\mathrm{II}}$ through the engine compartment is expressed as follows:

$$
\mathrm{q}_{\text {II }}=\mathrm{O}_{\text {II }} \sqrt{\frac{2 \Delta \mathrm{Pi}_{\text {II }}}{\rho}}
$$

The knowledge of the flow rate $\mathrm{q}_{\mathrm{II}}$ through the engine compartment requires those of aperture $\mathrm{O}_{\mathrm{II}}$. The decomposition of circuit II into three circuits arranged in series (circuits 1,10 and 9) gives:

$$
\frac{1}{\mathrm{O}_{\mathrm{II}}^{2}}=\frac{1}{\mathrm{O}_{1}^{2}}+\frac{1}{\mathrm{O}_{10}^{2}}+\frac{1}{\mathrm{O}_{9}^{2}}
$$

These three apertures are determined analytically by pressure drop estimations from Idel'Cik [20] and Ménard [21]. Six geometrical singularities are considered: a change of direction, an abrupt widening, an abrupt contraction, a progressive widening, a progressive contraction and an abrupt opening into an infinite space. Aperture $\mathrm{O}_{10}$ is calculated by using an equivalent circuit between the inlet and outlet sections of the engine compartment. It then depends on apertures $\mathrm{O}_{2}, \mathrm{O}_{3 \mathrm{a}}, \mathrm{O}_{3 \mathrm{~b}}, \mathrm{O}_{4}, \mathrm{O}_{5}, \mathrm{O}_{6}, \mathrm{O}_{7}$ and $\mathrm{O}_{8}$. Finally, the determination of the aperture $\mathrm{O}_{1}$ necessitates the knowledge of the infinite upstream section $\mathrm{S}_{0}$ that can be determined, for a squareback vehicle, from the values of the drag and the average base static pressure coefficient [13]:

$$
\mathrm{S}_{0}=\mathrm{S}_{\text {ref }} \frac{\mathrm{C}_{\mathrm{D}}}{1-\mathrm{Cp}_{\text {base }}}
$$

Consequently, drag and static pressure measurements achieved in wind tunnel can be used to give an estimation of the flow rate $\mathrm{q}_{\mathrm{II}}$ through the engine compartment. Besides, the determination of an equivalent circuit between the inlet and outlet sections of the engine compartment allows the evaluation of the flow rates through each of the internal branches described in Fig. 14, particularly through the porous media. The values given by the model with experimental or numerical input data are compared to the numerical values obtained from control surfaces in Fig. 15. The results show that the model gives good estimations of the flow rates with a little overvaluation. The flow rate above the porous media is particularly overestimated and suggests an underestimation of the corresponding aperture. The use of an equivalent circuit between the inlet and outlet 
sections of the engine compartment then engenders an underestimation of the equivalent aperture, and explains the overestimation of the flow rate in the inlet section. Therefore, the apertures estimation from characteristic pressure drops needs a special attention.

The validation of the analytical model allows considering another application of it. Indeed, it can be used as a tool to predict the flow rates evolution in function of an internal geometrical modification. For instance, it can determine the evolution of the flow rate through the porous media when the aperture below and/or above is reduced. First, consider the total pressure drop $\Delta \mathrm{Pi}_{\mathrm{AC}}$ as invariant. Then, the apertures associated to the internal branches located above and below the porous media are reduced separately then simultaneously from 5\% to $30 \%$. The results presented in Fig. 16 show that despite a flow rate reduction in the inlet section, the apertures reduction engenders a flow rate increase through the porous media. This result agrees with the numerical results shown in Fig. 10. Therefore, the analytical model is a good predictive tool for the flow rate evolution and can be used at the early stages of an engine compartment development.

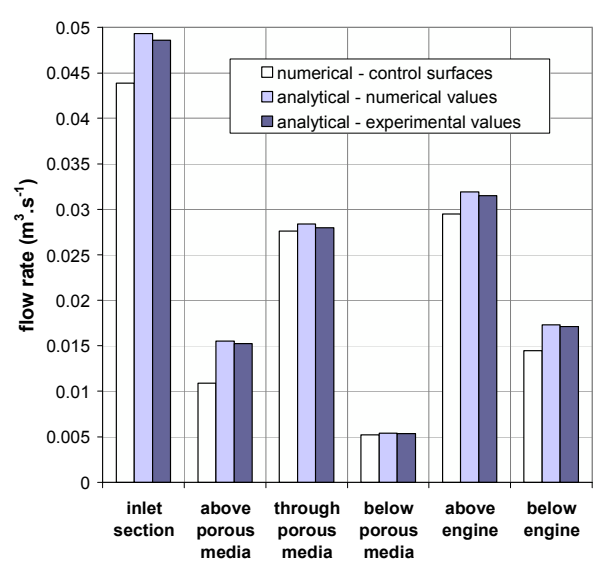

Fig. 15 Flow rates through the internal branches of the engine compartment

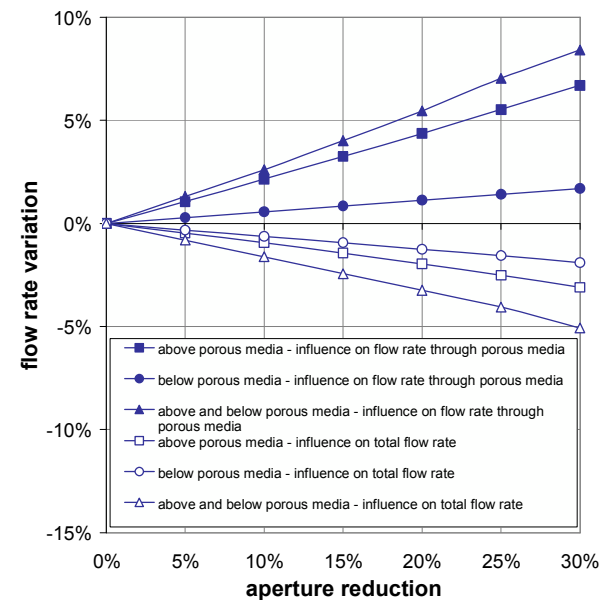

Fig. 16 Flow rates variations in function of the internal apertures reduction

\section{Conclusion}

Flow in the engine compartment is studied on a simplified car geometry equipped with an engine compartment by means of three approaches.

The experimental and numerical results show that configurations favorable to low drag values correspond to outlets located at the vehicle rear end. The cooling drag contribution in the total drag varies from $2 \%$ and $24 \%$ between rear end and underbody outlets. The introduction of momentum in the wake generated by the rear end outlets moves the vortices cores downstream from the geometry causing a base static pressure increase and a drag decrease.

Rear end outlets also favor the engine cooling in comparison to exits located in the underbody. Moreover, the use of seals above and below the porous media significantly increases the flow rate through it $(+45 \%)$ with little impact on the drag values $(-1.3 \%<$ $\left.\Delta \mathrm{C}_{\mathrm{D}}<+2.2 \%\right)$. 


\section{Flow in the engine compartment: analysis and optimization}

A uniform flow distribution on the porous media reduces its pressure loss and should therefore reduce the total pressure loss due to the geometry. Since it represents most of the drag, a uniform velocity distribution on the heat exchangers should induce a drag reduction.

Finally, an analytical model is set up and provides a simple and quick way to estimate the cooling flow rate from drag and static pressure measurements in wind tunnels. It also provides a prediction of the cooling flow rate evolution according to a geometrical modification of the air circuit.

\section{References}

[1] European Automobile Industry Report 2009/2010, ACEA, www.acea.be.

[2] Hucho, W.-H. (1978) 'The Aerodynamic Drag of Cars - Current Understanding, Unresolved Problems and Future Potential', in Sovran, G., Morel, T., Mason, W. T. [eds], 'Aerodynamic Drag Mechanisms of Bluff Bodies and Road Vehicles', Plenum Press, New York, pp. 7-44.

[3] Santer, R., Gleason, M. E. (1983) 'The Aerodynamic Development of the Probe IV Advanced Concept Vehicle', SAE 831000, Passenger Car Meeting, Dearborn, Michigan, June 6-9.

[4] Carr, G., W. (1995) 'The influence of Engine Cooling Airflow on Car Performance and Stability', C496/079/95, IMechE 1995, pp. 491-498.

[5] D’Hondt, M. (2010) 'Traînée et débit des compartiments moteurs de véhicules automobiles', 254 pp., Thèse : Mécanique et Energétique, Orléans.

[6] Ivanic, T., Gilliéron, P. (2005) 'Reduction of the Aerodynamic Drag due to Cooling Systems : an Analytical and Experimental Approach', SAE Technical Paper Series 2005-01-1017, World Congress, Detroit, Michigan.

[7] Tai, C., H., Cheng, C., G., Liao, C., Y. (2007) 'A Practical and Simplified Airflow Simulation to Assess Underhood Cooling Performance', SAE Technical Paper Series 200701-1402, World Congress, Detroit, Michigan.

[8] Alajbegovic, A., Xu, B., Konstantinov, A., Amodeo, J., Jansen, W. (2007) 'Simulation of Cooling Airflow under Different Driving Conditions', SAE Technical Paper Series, World Congress, Detroit, Michigan.

[9] Williams, J., E., Oler, J., W., Hackett, J., E., Hammar, L. (1991) 'Water Flow Simulation of Automotive Underhood Airflow Phenomena', SAE 910307.

[10] Ohshima, T., Hamatani, K., Ninoyu, M., Nakagawa, K. (1997) 'Influence of the cooling air flow outlet on the aerodynamic characteristics', SAE of Japan, JSAE Review 19 (1998), pp. 137-142.

[11] Barnard, R., H. (2000) 'Theoretical and experimental investigation of the aerodynamic drag due to automotive cooling systems', IMechE 2000, Proc Instn Mech Engrs, Vol 214 Part D, pp. 919-927.

[12] Jama, H., Watkins, S., Dixon, C., Ng, E. (2004) 'Airflow Distribution through the Radiator of a Typical Australian Passenger Car', 15th Australian Fluid Mechanics Conference, Sydney, Australia.

[13] Chometon, F., Gilliéron, P. (1996) 'Modélisation des écoulements tridimensionnels décollés autour des véhicules automobiles à l'aide d'un modèle à zéro-dimension, SIA 96.09.11, Courbevoie, France.

[14] Ahmed, S., R., Ramm, G., Faltin, G. (1984) 'Some salient features of the time-averaged ground vehicle wake', SAE 840300.

[15] Duell, E., G., George, A., R. (1999) 'Experimental study of a ground vehicle body unsteady near wake', SAE 1999-01-0812, Detroit, USA. 
D'Hondt M., Gilliéron P., Devinant P.

[16] Rouméas, M. (2006) 'Contribution à l'analyse et au contrôle des sillages de corps épais par aspiration ou soufflage continu', Thèse de l'Institut National Polytechnique de Toulouse.

[17] Depeyras, D. (2009) 'Contrôle actifs et passifs appliqués à l'aérodynamique automobile', Thèse de l'université de Bordeaux I.

[18] PowerFlow User's Guide, Release 4.0, Exa Corporation, Boston, Massachusetts (2006).

[19] Onorato, M., Costelli, A., F., Garonne, A. (1984) 'Drag measurement through wake analysis', SAE International Congress and Exhibition, SP6569, pp. 85-93, Detroit.

[20] Idel'Cik, I., E. (1986) 'Mémento des pertes de charge. Coefficients de pertes de charge singulières et de pertes de charge par frottement', Ed. Eyrolles, ISSN 0399-4198.

[21] Ménard, M. (1978) Cours de Mécanique des Fluides, Conservatoire National des Arts \& Métiers, Paris. 